\title{
Hot, dense, millimeter-scale, high-Z plasmas for laser-plasma interactions studies
}

\author{
B. H. Failor ${ }^{1, *}$ J. C. Fernandez, ${ }^{1}$ B. H. Wilde, ${ }^{1}$ A. L. Osterheld, ${ }^{2}$ J. A. Cobble, ${ }^{1}$ and P. L. Gobby ${ }^{1}$ \\ ${ }^{1}$ Los Alamos National Laboratory, P.O. Box 1660, Los Alamos, New Mexico 87545 \\ ${ }^{2}$ Lawrence Livermore National Laboratory, P.O. Box 808, Livermore, California 94551
}

(Received 17 August 1998; revised manuscript received 4 January 1999)

\begin{abstract}
We have designed and produced hot, millimeter-scale, high- $Z$ plasmas of interest for National Ignition Facility hohlraum target design. Using a high- $Z$ gas fill produces electron temperatures in the $3.5-6-\mathrm{keV}$ range, the highest temperatures measured to date for high-density $\left(10^{21} \mathrm{e} / \mathrm{cm}^{3}\right)$ laser-heated plasmas, and much higher than the $3 \mathrm{keV}$ found for low- $Z$ (neopentane) fills. These measurements are in good agreement with the target design calculations, and the $L$-shell spectroscopic approach used to estimate the electron temperature has certain advantages over traditional $K$-shell approaches. [S1063-651X(99)15205-X]
\end{abstract}

PACS number(s): 52.50.Jm, 52.25.Nr, 52.35.Nx, 52.70.La

\section{INTRODUCTION}

The National Ignition Facility (NIF) will implode fuel capsules in laser-heated hohlraums to investigate the physics of fusion ignition and burn in the laboratory. Plasma produced in these hohlraums can potentially reflect away a large fraction of the incident laser energy via laser plasma instabilities (LPI's), such as stimulated Brillouin scattering (SBS) and stimulated Raman scattering (SRS). NIF-scale plasmas have been produced in the laboratory in order to estimate the expected scattered light levels [1]. Both the low- $Z$ gas fill and the high- $Z$ material ablated from the hohlraum wall produce plasmas susceptible to, or that can support, LPI. $K$-shell $\mathrm{x}$-ray emission from dopants, such as $\mathrm{Ti} / \mathrm{Cr}[2-4]$ and $\mathrm{Ar} / \mathrm{Cl}$ [5], have provided estimates of electron temperature $T_{e}$ in low- $Z$ gas fills. In this paper we describe target designs developed to investigate SRS and SBS in high- $Z$ gas-fill plasmas, and how we have used $L$-shell $x$-ray emissions to estimate the $T_{e}$ in these plasmas. The measured electron temperatures for these high- $Z$ fills, $3.5-6 \mathrm{keV}$, are much higher than for low- $Z$ fills ( $3 \mathrm{keV}$ for neopentane) and are actually the highest temperatures measured to date for highdensity $\left(10^{21} \mathrm{e} / \mathrm{cm}^{3}\right)$ laser-heated plasmas. For this reason the plasmas are of interest for efficient generation of $x$ rays in the 4-7 keV energy range [6]. These $T_{e}$ estimates are compared with results from a numerical design tool, LASNEX [7], which is used to predict NIF hohlraum performance. $T_{e}$ is an important parameter in these high- $Z$ plasmas because it can determine the types of instabilities that are most active [8]. Although the $L$-shell $x$-ray emission is more difficult to calculate, it has some advantages over $K$-shell emission as a temperature diagnostic, including faster time response, better signal-to-noise ratio, and flatter instrument sensitivity.

\section{APPROACH}

In this section we describe the experimental conditions, the diagnostic measurements, and the numerically predicted scaling of line ratios. The experimental conditions can be

\footnotetext{
*Permanent address: Maxwell Physics International, 2700 Merced Street, San Leandro, CA 94577.
}

$1063-651 X / 99 / 59(5) / 6053(5) / \$ 15.00$

PRE $\underline{59}$ considered the "system inputs," and the diagnostic measurements the "system outputs."

The system inputs include the target and the laser. For this set of experiments, toroidal hohlraum targets were shot. The hohlraum has a $25-\mu \mathrm{m}$-thick gold wall, and is $3.6 \mathrm{~mm}$ in diameter and $1.6 \mathrm{~mm}$ in length. The hohlraum corners are not sharp, but rather have a $0.7-\mathrm{mm}$ radius of curvature [9]. Often a $185-\mu \mathrm{m}$ diagnostic slot was present at the hohlraum midplane, sealed with $0.6-$ or $1.0-\mu \mathrm{m}$-thick Mylar, which allowed the spectrograph (described below) to look into the center of the hohlraum. The primary fill gas was xenon (Xe), with deuterium $\left(D_{2}\right)$ or neopentane $\left(\mathrm{C}_{5} \mathrm{H}_{12}\right)$ sometimes added. The gas fill was sealed inside the hohlraum with silicon nitride windows glued on each end.

The laser energy entered the hohlraum through the two silicon nitride windows [9]. The ten Nova beams, five incident from the east and five from the west, were operated in the blue at $351 \mathrm{~nm}$. To obtain the desired plasma conditions, a 1.4-nsec-long laser pulse, rising about $50 \%$ in power with time, was used. Nine beams turned on simultaneously to ionize and heat the target plasma. A tenth beam, which acted as the SBS/SRS probe, turned on later, when the desired hot, long-scale-length plasma was formed.

The plasma conditions that LASNEX predicts at $0.9 \mathrm{nsec}$ from the beginning of the heating pulse for a $67 \% \mathrm{Xe}$ and $33 \% D_{2}$ fill are shown in Fig. 1. The different parameters are plotted versus the distance along the laser beam path, from the window to the wall. The weak density and temperature gradients are expected to be conducive to LPI growth.

The Xe emission lines (the "system outputs," in this case) were measured using spatially and time-resolving crystal spectrographs [2]. Multichannel-plate (MCP) based gated $\mathrm{x}$-ray imagers (GXI's) with four strip lines, each recorded four independently timed spectra on each shot. An array of horizontal slits spatially resolved the spectra in the vertical direction, and a flat TIAP crystal provided spectral dispersion. As indicated in Fig. 2, measurements were made along three different lines of sight: laser entrance hole (LEH), laser beam path, and midplane. As discussed below, the plasma conditions and the volume of plasma viewed along these lines of sight were different.

A numerical model [10] predicts how the Xe emission depends on plasma conditions. Xe 3-2 transitions have been 


\section{DISCLAIMER}

This report was prepared as an account of work sponsored by an agency of the United States Government. Neither the United States Government nor any agency thereof, nor any of their employees, make any warranty, express or implied, or assumes any legal liability or responsibility for the accuracy, completeness, or usefulness of any information, apparatus, product, or process disclosed, or represents that its use would not infringe privately owned rights. Reference herein to any specific commercial product, process, or service by trade name, trademark, manufacturer, or otherwise does not necessarily constitute or imply its endorsement, recommendation, or favoring by the United States Government or any agency thereof. The views and opinions of authors expressed herein do not necessarily state or reflect those of the United States Government or any agency thereof. 


\section{DISCLAIMER}

Portions of this document may be illegible in electronic image products. Images are produced from the best available original document. 

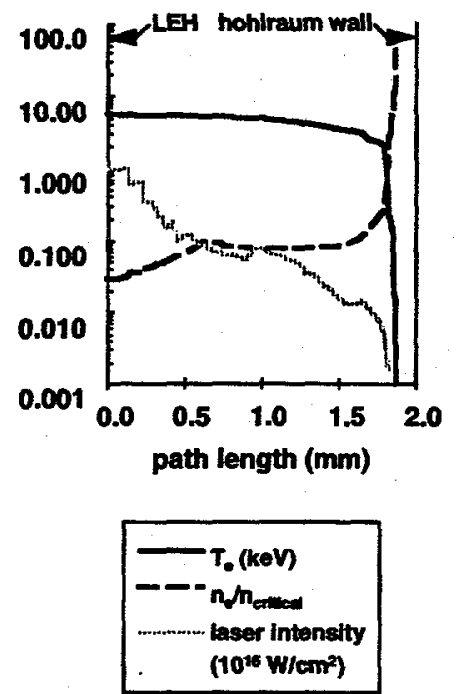

FIG. 1. LASNEX predictions for electron temperature $\left(T_{e}\right)$ and electron density $\left(n_{e}\right)$ along the laser beam path from laser entrance hole (LEH) to hohlraum wall at $0.9 \mathrm{nsec}$ after start of laser pulse. The hohlraum was filled with a $67 / 33$ mixture of $X e / D_{2}$, and the laser was fired at full power $(30 \mathrm{~kJ}) . T_{e}$ in the LEH is $5.4 \mathrm{keV}$.

used to estimate core conditions in inertial confinement fusion implosions [10], but we have focused on Xe 4-2 lines that have been used in the past to diagnose magnetic fusion plasmas [11], namely, the Ne-like $2 p_{3 / 2}-4 d_{5 / 2}$ resonant line and the $\mathrm{Na}$ like $3 l 4 l^{\prime}$ satellite. The same 4-2 transitions for $Y$ have been measured in another laser-produced plasma [12]. Mg-like satellite emission is also present, but predicting its level is much more complex computationally because so many additional atomic levels are needed for the calculation. A plot of how the Na-like to Ne-like ratio varies with electron temperature at two different electron densities, $10^{20}$ and $10^{21} \mathrm{e} / \mathrm{cm}^{3}$, is shown in Fig. 3. Given only that the electron density lies between these two limits, the uncertainty in the predicted temperature increases with temperature, from \pm 0.2 $\mathrm{keV}$ at $3 \mathrm{keV}$ to $\pm 0.8 \mathrm{keV}$ at $6 \mathrm{keV}$. The ratio was calculated in steady state, which is justified because the ionization times for $\mathrm{Ne}$ - and $\mathrm{Na}$-like ions vary from 190 to $60 \mathrm{psec}$ and from

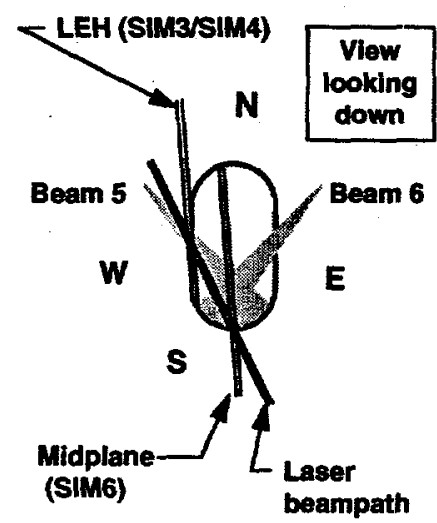

(SiM1)

FIG. 2. Xe 42 spectra were measured from different views. Spectrographs were fielded in 6-in. manipulators (SIM's) on the Nova ten-beam target chamber and the effective source width in all cases was $80-140 \mu \mathrm{m}$. The illumination patterns of two laser beams are also shown.

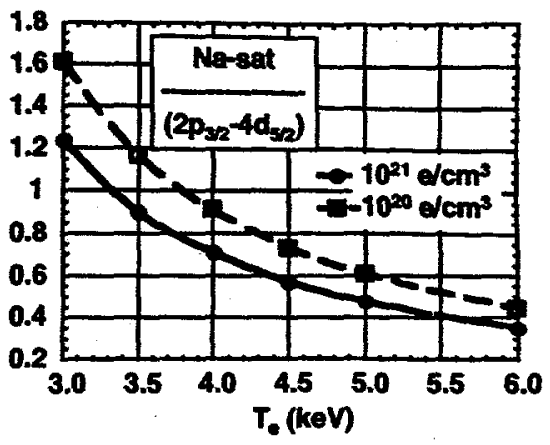

FIG. 3. The Xe 4-2 line ratio as a function of $T_{e}$ for two different electron densities, $10^{20}$ and $10^{21} \mathrm{e} / \mathrm{cm}^{3}$.

40 to 20 psec, respectively, for $3 \mathrm{keV} \leqslant T_{e} \leqslant 6 \mathrm{keV}$ and an electron density of $10^{21} \mathrm{e} / \mathrm{cm}^{3}$.

\section{RESULTS}

To compare LASNEX predictions with the experiment, we have focused on the LEH line of sight. As noted above, we have concentrated our analysis on the 4-2 transitions, even though emission from 3-2 transitions were also detected. There are two reasons for this: first, the transitions corresponding to different ionization states ( $\mathrm{Ne}, \mathrm{Na}, \mathrm{Mg}$, etc.) are more clearly separated; and second, the lines should be more optically thin, reducing the importance of radiation transport. Radiation transport issues are also why we use the LEH lineof-sight data. We found that the LEH spectra vary as the laser power and gas fill change, while the spectra from other lines of sight do not. In particular, spectra acquired along the midplane line of site are remarkably constant. We attribute this to high line opacity, even for the 4-2 transitions. LASNEX predicts that the Xe plasma close to the hohlraum wall is much cooler than that directly heated by the laser beams.

An example of a Xe spectrum from the LEH line of sight is shown in Fig. 4. These data, recorded 1 nsec after the start of the laser pulse, correspond to a shot taken at low laser power with a $100 \% \mathrm{Xe}$ fill. The spectrum is spatially resolved and indicates that the $\mathrm{X}$-ray emission is contained within a radius of $0.5 \mathrm{~mm}$, the region most strongly heated by the incident laser beams. A spectral lineout from the data shows the locations of the 4-2 lines used to estimate $T_{e}$, as well as the 3-2 lines. An example of how the 4-2 lines were

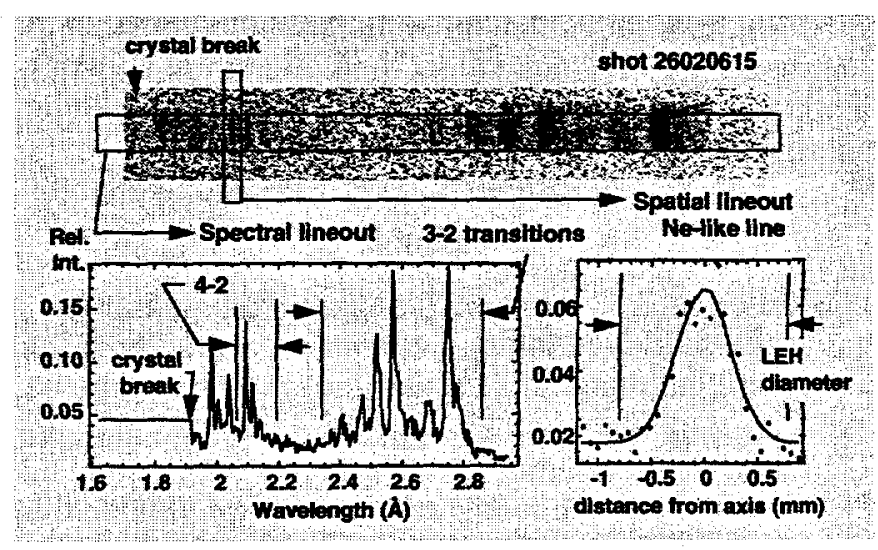

FIG. 4. A time- and space-resolved Xe spectrum obtained from a $100 \%$ Xe-filled hohlraum shot at low laser power $(12.5 \mathrm{~kJ})$. 


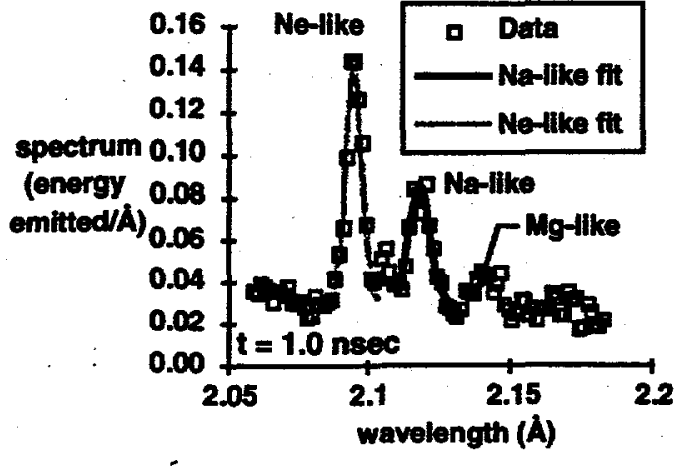

FIG. 5. Fitted Xe 4-2 spectrum obtained from a $100 \%$ Xe-filled hohlraum shot at low laser power $(12.5 \mathrm{~kJ})$. Analysis, using a $3.4 \times 10^{20} \mathrm{e} / \mathrm{cm}^{3}$ electron density (predicted by LASNEX), indicates $4.4 \mathrm{keV}<T_{e}<5.3 \mathrm{keV}$.

fit is given in Fig. 5. The uncertainties in the Ne- and Na-like line areas, which resulted in the stated $T_{e}$ uncertainties, were estimated by comparing a Gaussian fit with a simple trapezoidal integration.

We used the ratio of the line areas to estimate the electron temperature, without additional compensations. Because the ionization rates $(\sim 30 \mathrm{psec}$ for $\mathrm{Na}$-like $\mathrm{Xe}$, see above) are short compared to the laser heating pulse ( $1.4 \mathrm{nsec})$, the ionization balance, and therefore the line emission, is expected to track the plasma temperature. The signal-to-noise ratio is good because the line ratio is relatively close to unity, 0.4 to 1.4 , in the expected temperature range. And the instrument response, which includes the photocathode sensitivity, crystal reflectivity, and pulsed gain uniformity of the GXI strip line, were assumed equal for the two lines because they are separated in energy by less than $0.06 \mathrm{keV}$ and in space by less than $0.5 \mathrm{~mm}$ on the imager. Like this $L$-shell spectral approach, an isoelectronic $K$-shell $(\mathrm{Ti} / \mathrm{Cr}$ or $\mathrm{Ar} / \mathrm{Cl})$ measurement [2-4] should have a good temporal response and signal-to-noise ratio, but the larger energy separation between the lines leads to uncertainties in the instrument response with respect to the photocathode efficiency, crystal reflectivity, and pulsed strip-line gain. On the other hand, a satellite to resonant line ratio measurement [5], for which the lines are physically close together on the imager, would have a relatively flat instrument response and, again, good temporal response. But the expected line ratios will be large, in the range of 10 to 40 or 100 , which approaches the full linear dynamic range of a gated MCP device and limits the signalto-noise ratio. The $L$-shell measurement has a fast temporal response, good signal-to-noise ratio, and a flat instrument response, but the line ratios are much more difficult to calculate because of the large number of transitions that contribute to the Na-like satellite line. The $L$-shell approach should find broader application as the computational tools required to predict the spectra become more widely available.

We find that agreement between LASNEX and the measurements is quite good. Table I summarizes the measurements and predictions at about $1 \mathrm{nsec}$ from the start of the laser pulse. $T_{e}$ was estimated from the ratio of the $\mathrm{Ne}$ - and Na-like line areas, using the electron density predicted by LASNEX, which was between $10^{20}$ and $10^{21} \mathrm{e} \mathrm{cm}^{3}$. Generally, $T_{e}$ increases with increasing Xe fraction due to increased inverse Bremsstrahlung absorption. In all cases the values agree within the stated uncertainties. Because the sensitivity of the line ratio to $T_{e}$ decreases with increasing $T_{e}$, the experimental uncertainties are larger at higher temperatures. The stated LASNEX uncertainty of $0.5 \mathrm{keV}$ is an estimate based on limitations in the code's models for laser light absorption and heat conduction. This value may be high, since an uncertainty of $0.2 \mathrm{keV}$ is all that is needed to obtain agreement with experiment.

The electron temperature increases with the $Z$ of the gas fill, even though $x$-ray emission from the plasma increases as well. This is because inverse bremsstrahlung absorption [13] increases strongly with $Z$. An expression for the absorption coefficient is given below:

$$
\begin{gathered}
\kappa_{i b}=\frac{8 n_{e}^{2} r_{e}^{3} \lambda_{L}^{2}}{3 \sqrt{2 \pi\left(1-n_{e} / n_{c}\right)}} \frac{Z \ln \Lambda}{T_{e}^{1.5}}, \\
\Lambda \equiv \frac{c T_{e}}{\omega_{p} p_{\min }}, \\
p_{\min } \equiv \max \left[\frac{Z r_{e}}{T_{e}}, \frac{\lambda_{e}}{T_{e}^{0.5}}\right],
\end{gathered}
$$

where $n_{e}$ is the electron density (taken to be $0.1 n_{c}$ ), $r_{e}$ is the classical electron radius $\left(2.82 \times 10^{-13} \mathrm{~cm}\right), \lambda_{L}$ is the laser wavelength $(0.351 \mu \mathrm{m}), Z$ is the average charge state of the ions, $n_{c}$ is the critical electron density corresponding to $\lambda_{L}$ $\left(10^{22} \mathrm{~cm}^{-3}\right), T_{e}$ is the electron temperature in units of the electron rest mass $(511 \mathrm{keV}), c$ is the speed of light in vacuum, $\omega_{p}$ is the electron plasma frequency corresponding

TABLE I. $T_{e}$ in laser entrance hole depends on fill gas and laser energy. Measurements are in good agreement with LASNEX predictions.

\begin{tabular}{lccc}
\hline \hline $\begin{array}{l}\text { Gas } \\
\text { fill }\end{array}$ & $\begin{array}{c}\text { Laser energy } \\
(\mathrm{kJ})\end{array}$ & $\begin{array}{c}T_{e}(\mathrm{keV}) \\
\text { data }(0.9-1.25 \mathrm{nsec})\end{array}$ & $\begin{array}{c}T_{e}(\mathrm{keV}) \\
\text { LASNEX }(0.9 \mathrm{nsec})\end{array}$ \\
\hline $100 \% \mathrm{Xe}$ & 30 & & 5.9 \\
$67 \% \mathrm{Xe} / 33 \% \mathrm{D}_{2}$ & 30 & $5.5 \pm 0.7$ & 5.4 \\
$100 \% \mathrm{Xe}$ & 12.5 & $4.9 \pm 0.4$ & 4.3 \\
$70 \% \mathrm{Xe} / 30 \% \mathrm{C}_{5} \mathrm{H}_{12}$ & 12.5 & $3.9 \pm 0.3$ & 4.0 \\
$50 \% \mathrm{Xe} / 50 \% \mathrm{C}_{5} \mathrm{H}_{12}$ & 12.5 & $3.7 \pm 0.1$ & $3.6 \pm 0.5$ \\
\hline \hline
\end{tabular}


TABLE II. The much higher inverse bremsstahlung absorption in Xe will result in a higher $T_{e}$, in spite of increased extreme ultraviolet emission.

\begin{tabular}{lclrrrr}
\hline \hline & & \multicolumn{5}{c}{$T_{\varepsilon}(\mathrm{keV})$} \\
\cline { 4 - 7 } Fill & $Z$ & & 0.5 & 1.5 & 3 & 6 \\
\hline Neopentane & 2.5 & Absorption length (mm) & 0.82 & 3.62 & 9.35 & 24.31 \\
Xe & 44 & & 0.07 & 0.27 & 0.64 & 1.56 \\
& & Ratio (neopentane/Xe) & 11.02 & 13.41 & 14.58 & 15.56 \\
Neopentane & 2.5 & Transmission to 2 mm & $8.79 \%$ & $57.58 \%$ & $80.74 \%$ & $92.10 \%$ \\
Xe & 44 & (Hohlraum wall location) & $0.00 \%$ & $0.06 \%$ & $4.42 \%$ & $27.80 \%$ \\
\hline \hline
\end{tabular}

to $n_{e}\left(1.69 \times 10^{15} \mathrm{rad} / \mathrm{sec}\right)$, and $\lambda_{e}$ is the Compton electron wavelength $\left(3.86 \times 10^{-11} \mathrm{~cm}\right)$. A number of values for the inverse bremsstrahlung absorption length $\left(\kappa_{\mathrm{ib}}{ }^{-1}\right)$ are given in Table II for neopentane $\left(\mathrm{C}_{5} \mathrm{H}_{12}\right)$ and pure Xe fills, assuming that the neopentane is fully stripped and the $\mathrm{Xe}$ is in the neonlike ionization state. Shown as well are the ratio of the neopentane to Xe absorption length and the percentage transmission of the laser beam through $2 \mathrm{~mm}$ of plasma (about the distance from the LEH to the hohlraum wall along the laser beam path). Note that the volumetric heating rate of the plasma, given by the product of the laser intensity and the inverse bremstrahlung absorption coefficient, $I_{L} \kappa_{\mathrm{ib}}$, is 10 to 15 times higher for $\mathrm{Xe}$ at the $\mathrm{LEH}$, where the laser first encounters the plasma. For this reason, even if greater than $75 \%$ of the incident laser energy is radiated away as UV and $x$-ray photons, there is sufficient absorbed energy to sustain an electron temperature that is $2-3$ times higher in $\mathrm{Xe}$, as compared to neopentane. Also, once the neopentane reaches $3 \mathrm{keV}$, over $80 \%$ of the incident laser energy is predicted to reach the hohlraum wall, while in the case of $\mathrm{Xe}$ this number is only $4 \%$. Due to its higher $Z$, the Xe fill plasma can efficiently absorb the laser energy at higher electron temperatures, which increases the peak temperatures that can ultimately be reached.

\section{CONCLUSIONS}

In summary, we have estimated $T_{e}$ in the LEH region of Xe-filled hohlraums from Xe 4-2 x-ray spectra, and have found the measurements to be in good agreement with LASNEX predictions, with $3.5 \mathrm{keV}<T_{e}<6 \mathrm{keV}$ for $10^{20} e / \mathrm{cm}^{3}<n_{e}<10^{21} e / \mathrm{cm}^{3}$. This agreement increases our confidence in LASNEX as an accurate modeling and predictive tool for these targets. These measurements are also important to understanding the growth and saturation of laser plasma instabilities for plasma conditions expected in NIF hohlraums [8]. New approaches are needed to obtain $T_{e}$ measurements at the midplane of these targets, because plasma opacity and radiation transport cloud the issue. For $T_{e}$ above 4 $\mathrm{keV}, K$-shell emission from $\mathrm{Kr}$ and $\mathrm{Br}(12 \mathrm{keV}<E$ $<13 \mathrm{keV}$ ) may be useful for this measurement. A much more challenging goal is the measurement of the electron energy distribution function itself, rather than the moment corresponding to a temperature.

\section{ACKNOWLEDGMENTS}

We thank the Nova Operations Team, the Los Alamos technicians supporting Nova, the Target Fabrication Group at Los Alamos, K. Gifford (GA), and G. Stone (LLNL). This work was supported by the U.S. DOE.
[1] See, for example, B. J. MacGowan, B. B. Afeyan, C. A. Back, R. L. Berger, G. Bonnaud, M. Casanova, B. I. Cohen, D. E. Desenne, D. F. DuBois, A. G. Dulieu, K. G. Estabrook, J. C. Fernandez, S. H. Glenzer, D. E. Hinkel, T. B. Kaiser, D. H. Kalantar, R. L. Kauffman, R. K. Kirkwood, W. L. Kruer, A. B. Langdon, B. F. Lasinski, D. S. Montgomery, J. D. Moody, D. H. Munro, L. V. Powers, H. A. Rose, C. Rousseaux, R. E. Turner, B. H. Wilde, S. C. Wilks, and E. A. Williams, Phys. Plasmas 3, 2029 (1996), and references therein.

[2] B. H. Failor, W. W. Hsing, R. G. Hockaday, T. D. Shepard, D. E. Klem, D. H. Kalantar, and B. J. MacGowan, Rev. Sci. Instrum. 66, 767 (1995).

[3] C. A. Back, R. L. Berger, K. Estabrook, B. H. Failor, W. W. Hsing, E. J. Hsieh, R. Hockaday, D. H. Kalantar, R. L. Kauffman, C. J. Keane, D. E. Klem, B. J. MacGowan, D. S. Montgomery, J. D. Moody, L. V. Powers, T. D. Shepard, G. F. Stone, L. J. Suter, and R. E. Turner, J. Quant. Spectrosc. Radiat. Transf. 54, 27 (1995).

[4] T. Shepard, C. A. Back, D. H. Kalantar, R. L. Kauffman, C. J.
Keane, D. E. Klem, B. F. Lasinski, B. J. MacGowan, L. V. Powers, L. J. Suter, R. E. Turner, B. H. Failor, and W. W. Hsing, Rev. Sci. Instrum. 66, 749 (1995); Phys. Rev. E 53, 5291 (1996).

[5] S. H. Glenzer, C. A. Back, K. G. Estabrook, B. J. MacGowan, D. S. Montgomery, R. K. Kirkwood, J. D. Moody, D. H. Munro, and G. F. Stone, Phys. Rev. E 55, 927 (1996), and references therein.

[6] J. Grun et al., IEEE International Conference on Plasma Science Cat. No. 97CH36085, 1997, p. 124; C. A. Back, J. Grun, C. D. Decker, J. L. Davis, O. L. Landen, L. J. Suter, and R. Wallace, Applications of X Rays Generated from Lasers and Other Bright Sources [Proc. SPIE 3157, 130 (1997)].

[7] B. H. Wilde et al, in Laser Interaction and Related Plasma Phenomena, 12th International Conference, Osaka, 1995, edited by S. Nakai and G. A. Mileypu, AIP Conf. Proc. No. 369 (AIP, Woodbury, NY, 1996), p. 255.

[8] J. C. Fernandez, J. A. Cobble, B. H. Failor, D. F. DuBois, David S. Montgomery, Harvey A. Rose, Hoanh X. Vu, Bern- 
hard H. Wilde, Mark D. Wilke, and Robert E. Chrien, Phys. Rev. Lett. 77, 2702 (1996).

[9] J. C. Fernandez, J. A. Cobble, B. H. Failor, W. W. Hsing, H. A. Rose, B. H. Wilde, K. S. Bradley, P. L. Gobby, R. Kirkwood, H. N. Kornblum, D. S. Montgomery, and M. D. Wilke, Phys. Rev. E 53, 2747 (1996).

[10] C. J. Keane, B. A. Hammel, A. J. Osterheld, and D. R. Kania, Phys. Rev. Lett. 72, 3029 (1994).
[11] P. Beiersdorfer (private communication); P. Beiersdorfer, S. von Goeler, M. Bitter, E. Hinnov, R. Bell, S. Bernabei, J. Felt, K. W. Hill, R. Hulse, J. Stevens, S. Suckewer, J. Timberlake, A. Wouters, M. H. Chen, J. H. Scofield, D. D. Dietrich, M. Gerassimenko, E. Silver, R. S. Walling, and P. L. Hagelstein, Phys. Rev. A 37, 4153 (1988).

[12] A. L. Osterheld et al., Phys. Scr. 54, 240 (1996).

[13] T. W. Johnston and J. Dawson, Phys. Fluids 16, 722 (1973). 